\title{
Astrology and Science: A Precarious Relationship Part 2: Consideration of Empirical Investigations on the Validity of Astrology
}

\author{
Gerhard MAYer \\ Institut für Grenzgebiete der Psychologie und Psychohygiene, Freiburg i. Br./Germany \\ mayer@igpp.de
}

Submitted October 14, 2019; Accepted March 20, 2020; Published December 15, 2020

DOI: 10.31275/20201697

Creative Commons License CC-BY-NC

\begin{abstract}
In Part 2 of "Astrology and Science: A Precarious Relationship," the results of some population surveys are first presented to reveal definitory problems in determining astrology. When investigating "astrology," of crucial importance are which concepts and practices to include. After definitional clarification, the anomalistic aspects of astrology or astrological practice are attended to with a distinction made between the above-below theorem as the traditional basic assumption of astrology and the possible psi phenomena that can occur in astrological counseling practice. Further sections describe problems in scientific studies on the validity of astrology. Such problems could have led to the failure of these efforts. Furthermore, specific methodological problems in the investigation of the above-below theorem and in matching tests are addressed.

Keywords: astrology; population surveys; definition; empirical studies; methodological problems; above-below theorem; psi phenomena
\end{abstract}

In the first part of this paper in the preceding article (Mayer, 2020), the development of astrology in German-speaking countries in the 2oth century was described, and was distinguished by a specific effort to reintegrate it into the academic sciences. This was mainly linked to the astrological anthropology of Thomas Ring (1892-1983). With his concept 
of the "cosmotype," which he understood as mediating between the genotype and the phenotype, Ring presented an ambitious model for a revised, modern understanding of astrology (Ring, 1956, 1959, 1969, 1972, 1973, 1975). This was supplemented by system-theoretical considerations (cf. Niehenke, 1994), and in its multidisciplinary conception represented an approach to astrology that would be insufficiently covered by the term "psychological astrology." Ring's theoretical approach combined with his successful, practical, astrological work led to a fruitful and long-standing collaboration with the founder of the Institut für Grenzgebiete der Psychologie und Psychohygiene (IGPP), Professor Hans Bender (1907-1991), who met him in Berlin in the late 1920s (Bender, 1984). ${ }^{.}$Bender wrote that Ring, with his "extensive literary life's work ...., made a decisive contribution to liberating astrology from the bickering of schools and sects and making it the subject of a comprehensive anthropology" (Bender, 1984, p. 225, translated by G.M.). Astrology remained one of the central topics of the IGPP's research program during Bender's lifetime. This is shown with the 56 scientific articles published in the period 1957-1996 in the Zeitschrift für Parapsychologie und Grenzgebiete der Psychologie, which was founded by Bender. The very first edition contained an article on the results of a sociological survey on astrology (Schmidtchen, 1957). The second issue contained three experimental studies (C. G. Jung, 1957/1958; Arno Müller, 1957/1958; Michel Gauquelin, 1957/1958). However, the research efforts remained contradictory in their results and negative in their tendency to prove a correlative relationship between astronomical constellations and events on Earth. In the following, I will deal with the problems of scientific approaches to and validation of astrology.

\section{ATTITUDES TOWARD ASTROLOGY_TOWARD WHICH ONE?}

If you look at population surveys on belief in and attitudes toward astrology, you will find questions such as "Do you believe that our zodiac sign determines our lives?" (TNS Infratest, 2012), "Do you believe in astrology?" (marktmeinungmensch, 2017), or "Do you believe that horoscopes can tell you something about what will happen in the future?" (YouGov, 2015), to name three examples. Nowhere is it specified which form of astrology is meant: the one at the level of 
newspaper horoscopes, the one in Astro TV shows, or the one with a trained astrological consultant, for instance. The survey results can then be correspondingly strange and difficult to interpret, as seen from the data from the above-mentioned YouGov survey. In this survey, launched in Germany, Great Britain, and the U.S., another question was asked about astrology, namely "Do you believe that star signs can tell you something about yourself or another person?"2 The first question concerns the prognostic, the second the personality psychological aspect of astrology. Table 1 shows the compilation of the results for the two questions asked in the three nations.

\begin{tabular}{|c|c|c|c|c|}
\hline \multicolumn{5}{|c|}{$\begin{array}{c}\text { TABLE } 1 \\
\text { Results of YouGov Survey (2015) on Astrology Questions } \\
\text { in Germany, Great Britain, and the United States }\end{array}$} \\
\hline Astrology Question & Nation & Females & Males & Total \\
\hline \multirow{3}{*}{$\begin{array}{l}\text { "Do you believe that horoscopes can } \\
\text { tell you something about what will } \\
\text { happen in the future?" }\end{array}$} & $\mathrm{D}$ & 21 & 9 & 15 \\
\hline & GB & 9 & 6 & 8 \\
\hline & USA & 19 & 10 & 14 \\
\hline \multirow{3}{*}{$\begin{array}{l}\text { "Do you believe that star signs can } \\
\text { tell you something about yourself or } \\
\text { another person?" }\end{array}$} & $\mathrm{D}$ & 20 & 11 & 16 \\
\hline & GB & 27 & 12 & 20 \\
\hline & USA & 39 & 21 & 30 \\
\hline
\end{tabular}

It can be seen that the affirmation of the two questions is significantly higher among women than among men-to my knowledge, this is consistent across all the different surveys. Looking at the values in a national comparison, one comes across the strange result that we find a clearly lower agreement among the British on the question of prognostic astrology. In contrast, in the question of personality astrology we find the lowest value in the Germans and a very high value in the sample in the U.S. How can this be interpreted? Perhaps that the Germans were thinking more of newspaper horoscopes in the second question, whereas the Americans have a better knowledge of personality astrology, which is reflected in the high approval rate? This is a possible explanation that cannot be derived from the data, because other plausible explanations could be at play. 
Using this example, I would like to show how meaningless population surveys of this kind are. We simply do not know the basis for the judgments. ${ }^{3}$ The National Science Board regularly collects data about attitudes in the U.S. regarding the field of science and technology, and regarding "pseudoscience," with astrology as an example of the latter. In representative surveys, Americans are asked to what extent they consider astrology to be scientific. The results for the data collected in 2012 show that $55 \%$ consider astrology as "not at all scientific," $10 \%$ as "very scientific," and 32\% as "sort of scientific" (NSF, 2014, 7/25-7/26). Here, again, the question arises, which form of astrology is the basis of the respective judgments.

\section{ASTROLOGY AND MATTERS OF DEFINITION}

In such contexts one cannot speak of a single astrology. One should take into account the heterogeneity of astrological practice and use this term in the plural (Campion \& Greene, 2011; Kelly, 1997). If one looks at the specialist literature and asks astrologers about their particular view of the nature of astrology, ${ }^{4}$ one gets quite different characterizations:

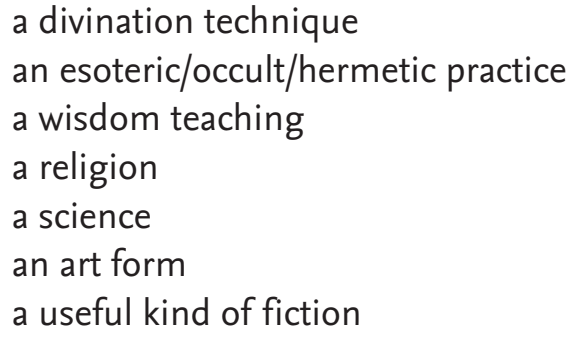

This list includes both practical forms and ideological basic assumptions, and once again illustrates the need for differentiation if a researcher wants to know what is being referred to.

The field of astrological forms of practice can be divided into different aspects. The historian Patrick Curry (1989), for example, created a hierarchical model based on the situation in the England of early modernity, with three forms of astrology that roughly corresponded to social classes. While the lower form concerned fortune-telling (on the street and during funfairs) and almanacs, the middle-form astrology 
dealt with the interpretation of horoscopes and complex prognostic work. Finally, the subject of high astrology was philosophical and theological speculation. In today's astrological practice, one finds the lower and middle forms; yellow-press astrology is among the first mentioned, and astrology that is based on individual horoscopes with complex calculations is among the latter. As I showed in Part I of this paper (the previous article in this journal issue), the offers available on certain Internet portals and in TV formats such as AstroTV could be seen as an intermediate form, since the consultations are based-at least apparently-on individual horoscopes while a thorough analysis of the individual's chart is lacking.

Differentiating astrology can also be structured in a various ways; for example, the purpose of application, according to which personality astrology can be distinguished from medical astrology, financial astrology, horary astrology, etc. Another possibility for structuring arises from the reference to the underlying worldview. Willis and Curry (2004, pp. 65 ff.) mention five forms in their chapter "Varieties of Astrological Experiences": (openly) divinatory astrology, neo-platonic, and hermetic astrology, Aristotelic and Ptolemaic astrology, scientific astrology and, finally, psychological astrology. This reasonable differentiation largely reflects a historical development and addresses the relatively early tension between spiritual-magical and rational approaches-a dichotomy that continues to play a major role. The distinction between scientific and psychological astrology implies that the latter does not refer to the form of psychology that is part of the academic sciences. The authors point out the great ambiguity regarding the ideological foundations of psychological astrology, which many practicing astrologers are reluctant to face:

There is a parallel here [between psychological astrology based on C. G. Jung's theory of archetypes-G.M.] . . . with the way both Ptolemy's and Aquinas's earlier ambiguous accommodation purchased a new lease on life for astrology in a fundamentally Aristotelian cosmos. To some extent, both share the price, namely acceptance of the basic (and fundamentally anti-divinatory) premise that the perceptible cosmos runs entirely 'naturally', material and even mechanistic principles with no direct spiritual input or dimension .... The result is an astrology, like a world, divided into those 
bits that can be naturalistically appropriated and a 'supernatural' remainder-at best inexplicable, but from a scientific-theoretical point of view, impossible, and therefore fraudulent. (Willis \& Curry, 2004, pp. 73-74)

With the increasing integration of classical approaches and horary astrology into contemporary astrological practice (see Part 1 , the previous article), we find a corresponding pluralization in the underlying worldviews. ${ }^{5}$

\section{ANOMALISTIC ASPECTS IN ASTROLOGY}

\section{The Above-Below Theorem and the Interpretation of Complex Horoscope Structures}

This paper aims to examine the relationship between science and astrology from the perspective of anomalistics as a field of research of science (Mayer et al., 2015) to which astrology belongs. A prerequisite for the assignment of astrology to the field of anomalistics is the assertion that astrology "functions" on a basis not yet fully understood and explainable with known scientific models. The assumption on which almost all forms of "Western" astrology are based asserts a connection between lawful astronomical circumstances, dynamics, movements (cosmic dimension), and earthly events as expressed in the much-quoted sentence from Hermes Trismegistos' Tabula Smaragdina "That which is below is like that which is above and that which is above is like that which is below." The astronomical elements relevant for astrology are attributed to a more or less fixed basic meaning, which, however, can undergo extensions and time-related modifications. The lawfulness, and thus also calculability, of astronomical dynamics, including the basic meaning attributed to them, represents a central prerequisite of astrological practice, i.e. regardless of possible extensions and modifications of the meaning of the astrological elements they are not interchangeable. "Mars," for example, cannot have the same meaning tomorrow as "Venus" has today. If one takes the (few) stable findings seriously, the assumed above-below connection represents a scientific anomaly.

Usually, this connection is experienced as evident in practical applications, such as the interpretation of a birth horoscope, or the 
creation of a prognostic or retrognostic horoscope. In this process of experiencing subjective evidence concerning the reliability and "truth" of astrology, another level comes into play, that of the interpreter and the receiver of the interpretation. It is no longer a matter of the theoretically modeled above-below connection, which should be as "pure" as possible, i.e. free of interpretational freedoms and decisionmaking necessities, but of a complex, often interpersonal interaction that is susceptible to influences of the most varied kinds.

Therefore, an important distinction is whether a scientific study of the validity of astrology investigates the "above-below theorem" (ABT [Oben-Unten-Theorem]; Wunder, 2005, p. 297) with the examination of a presumed connection between the existence of an astrological factor and a life-world fact as unambiguously as possible; or, whether the coherence or "hit rate" of astrologers is examined on the basis of interpreting complex horoscope structures, i.e. the performance of astrologers in general. This differentiation is reflected in two research paradigms, each with its own methodological problems (cf. Ertel, 2015). The first paradigm concerns the examination of isolated astrological assumptions, such as the assumption that, in the case of prominent athletes, Mars was more frequently near the Ascendant than expected by random chance, as Michel Gauquelin's well-known studies have shown; ${ }^{7}$ or that there are more interaspects ${ }^{8}$ to be found between the horoscopes of loving partners or friends than would be expected by chance (Mayer \& Garms, 2012), to name two examples. In the case of the second paradigm, empirical investigations usually apply to matching experiments. Astrologers, for example, are presented with horoscopes of politicians and painters, which they have to assign to the respective occupational groups on the basis of their analysis (Ertel, 1998); or they get ten horoscopes, and ten psychological reports, and must assign the related reports and horoscopes (Clark, 1960a, 1960b). With the second method, no direct proof of the validity of the ABT can be obtained from the results. Even excluding conventional possible explanations, the success of the astrologers could be attributed to other factors such as their psi ability (clairvoyance, etc.) in the case of a significantly positive result. The astrology skeptic (and former astrologer) Geoffrey Dean (1977, p. 554) writes about Clark's successful blind experiments mentioned above: "Whatever the explanation, it is clear that the 
significant blind trials have not demonstrated that astrology works but only that astrologers work."

Accordingly, if we assume the validity of astrology or astrological practice and exclude conventional explanations, we are dealing with or may be dealing with separate anomalies. ${ }^{9}$ The first concerns the ABT; the second can occur in the process of horoscope interpretation, and interaction with clients, the latter being describable by the concepts of parapsychological research.

\section{Astrology and Its Relation to Magic and Divination}

Referring to anomalistic processes, there are differences within various astrological methods. As described in Part 1 of this paper, astrologers such as Freiherr von Klöckler and Thomas Ring attempted to detach these forms of a revised astrology from the realm of magical ideas and practices and to make them compatible with the findings of modern natural sciences and academic psychology. They were critical of techniques based on magic conclusions by analogies that characterized classical astrology using directions to make prognostic statements. With these techniques, small periods of time are extrapolated according to a formula (direction key). In the case of secondary directions, one day corresponds to one year. Klöckler called them "fiktive Methoden" [fictitious methods] (1989, p. 153). The moment of birth, and the rhythmic return of patterns and elements are decisive for the forms of astrology promoted by these astrologers. At least in relation to more complex living organisms that go through a period of maturation during pregnancy before birth, i.e. before the beginning of existence as an independent organism, the birth chart can be understood as a kind of "Entlassungsschein," i.e. release certificate (Ring, 1975, p. 24). According to revised astrology, no direct causal effect relationship has to be assumed for the above-below connection due to an adjustment to cosmic rhythms: ${ }^{10}$

The above and the below are connected solely by the movement, physically the celestial mechanics, biologically and psychologically the life movement. Thus, the problem is reduced to whether, and to what extent, the changeable, volatile, and convertible can be implemented into the uniformly recurring. This is conceivable as the rhythmic integration of vital processes into the regular recur- 
rence of constellations of the solar system. (ibid., p. 13; emphasis in original; translation by G.M.)

Due to the clear definition of the "Aussagegrenzen," i.e. limits of validity, of astrology, which are determined by the genotype (heritage) and by the phenotype (environment), concrete astrology-based statements on events or the absolute level of personality characteristics (e.g., intelligence) are not considered possible in this model; the relationships to classical magical-occult thought are minimized. The anomaly consists of an insufficiently understood and correlatively assumed connection between astronomical conditions and structures and dynamics on the earthly plane. ${ }^{11}$ In other techniques, which are more strongly influenced by "classical astrology," hermetic patterns of interpretation or magical elements come into play to varying degrees. This is mostly evident in techniques that can be described as "astro-manticism" or "astro-divination." Some people don't count this as astrology. In an oracle situation, for example, a card is drawn from a deck of cards whose cards represent astrological elements, and its symbolic content is used to answer a question. "The difference [between the mantic and the astrological use-G.M.] lies in the game situation and the manipulation of the unconscious there, the logical opening up here" (Ring, 1972, p. 62). ${ }^{12}$ Relatively close to this method, although much more complex in its procedure, is the technique of horary astrology. There, a horoscope is calculated to exactly the point in time at which the question was asked. Since the questioner is usually unaware of the current ascendant and the house position of most planets, this method involves a similar element of chance to drawing an oracle card. The answer is then found from a relatively mechanical processing of certain fixed astrological rules of interpretation with greatly reduced complexity of the symbol structure. Many concrete details are obtained on the basis of analog-magic interpretation keys. For example, the degree distances to an exact aspect between signifiers are converted into time periods or geographical distances, so that two degrees distance to the exact point of aspect are translated into two days, month, years, or two meters, or kilometers, respectively. ${ }^{13}$

With these examples of techniques based on the astrological symbol system, the spectrum's range is marked by hardly referenced 
(in revised astrology) to specifically referenced (in horary astrology) to analog-magical thinking, to "pure divination." ${ }^{14}$ So here, too, in astrological practice, it is necessary to distinguish between the "pure divinatory principle" of operating with chance and the assumption that hermetic principles of the correspondences are effective on different levels and time scales, as well as the aforementioned aspect of psi in the astrologer, or interaction between astrologer and client. From an anomalistic-scientific perspective, no value judgment is associated with the distinction since all three forms of anomalies can occur. However, it will be harder to find explanations for the validity of analog-magic or hermetic laws than for the "purely divinatory technique" and for psi in the astrologer. The latter are provided by the known concepts of parapsychology.

\section{Astrology and Psi}

For some astrologers who remain interested in the ideological and scientific foundations of their practice, the assumption that the main factor for the successful "functioning" of astrology lies in the psi abilities of astrologers offers a way out of such dilemmas as the failure of many scientific tests and the much-discussed problem of a "correct" or successful interpretation of an erroneously calculated horoscope. ${ }^{15}$ Even for skeptics who question the central basic assumptions of astrology but do not generally reject every form of heterodox explanation, psi processes appear attractive as an illustrative model for the sparse empirical evidence in astrological classification experiments (e.g., Dean \& Kelly, 2003; Storm, 2007). ${ }^{16}$ Geoffrey Cornelius is one of the most explicit exponents of this thesis. He is a British practicing astrologer who has studied in depth the philosophical foundations of astrology and developed his own approach to astrology (Cornelius, 2003). With this he does not avoid dealing with fundamental problems for understanding the practice and "truth" of astrology, as Kochunas does in his essay "Why Astrology Works," and who describes astrology as an "Imaginal Discipline" which "must drop its pretensions to be an empirical discipline" (2000). ${ }^{17}$ It is therefore worth taking a closer look at Cornelius' approach. Familiar with the scientific experiments on the validity of astrology, he recognizes the empirical evidence, for example in the work of the Gauquelins. He also does not deny the 
widespread failure of astrologers in scientific experiments, including his own (Cornelius, 2003, pp. 64-65), which in no way corresponds to his subjective experience as a practitioner. From the scientific findings he draws conclusions, among other things:

Conventional astrological interpretation is not dependent on objective correlations.... Some unknown "other" element is involved in the astrological interpretation.... (This in turn suggests that the theoretical framework of traditional astrology is likewise inadequate to describe the phenomena.) ... This "other element" is broadly but frequently characterised, by astrologers and researchers alike, as either ESP or intuition.... The perception of astrology is founded in no special technique-experience does not improve it. . . The perception in astrology is not regular but unpredictable and nonregular. (It is not open to a rule and it appears to be a function of the situation and the participants. If it is a function of the situation, then it is also context-specific rather than universal.) (Cornelius, 2003, p. 67, emphases in the original)

For Cornelius, the practice of astrology is divination in the literal sense, sign interpretation, "questioning the gods," comparable with the practice of the I Ching. The latter even brought him to astrology (Cornelius, 1998). And as with the I Ching, there is a system of rules of interpretation of signs (astrological elements) in astrology, on the basis of which the divinatory statements are obtained, but the element of "coincidence" or "moment"-Cornelius' book is called The Moment of Astrology-plays the decisive role for the author: "The perception in astrology is not regular but unpredictable" (Cornelius, 2003, p.67). The astrologer is more comparable to an artist or magician (Cornelius, 2010, p. 15 f.) than to a practitioner who builds his success on the logical and experience-based application of a reliable system of symbols and their interpretations based on universal and natural laws. ${ }^{18}$ Even if-as in the case of Cornelius - the traditional application of astrological rules and techniques is considered necessary (see below), the ABT itself loses its fundamental significance and becomes a minor aspect of astrology.

Of course, you can see it that way-the field of astrology is large enough, and also the field of astromantics can be differentiated from the simple use of an astrological card deck to the sophisticated interpretation based on a complex system of symbols combined with 
a random process characteristic of divination. Cornelius acknowledges that "astrology does have a physical and objective presence, an occult mystery of the natural order of things" (1998), and that it contains objective phenomena that are even accessible to science. However, this is of little interest to the work of astrologers. He refers to these objective facts, as a classical distinction astrologia naturalis, while the astrologer's work concerns astrologia judicialis, i.e. judicial astrology. In this case, subjectivity prevails and the creative or visionary genius of the astrologer emerges. Accordingly, the experimental-statistical studies on validity are ineffective for astrological practice because they have nothing to do with it. ${ }^{19}$ " $(T)$ he main part of what we do is the interpretation of symbols to arrive at particular inferences and judgments, whether about character or about events in life. And this practice is divination, not science" (ibid.). To skeptics such as Paul Kurtz, he describes what astrologers would do as a "poetic interpretation of the heavens" (ibid.) and thus tries to undermine their criticism. This does not mean, however, that he would consider the learning and application of the technical side of astrology unimportant. Understanding astrology as an allegory (2003, pp. 288f.), Cornelius takes the astrological rules and symbols in their traditional meanings seriously and accordingly rejects, for example, artificially created or chosen planet positions (2010, pp. 13f.) because one "is doing something that begins to abuse the ritual of attending the world around us" (ibid., p. 14). He sees the practice of the astrologer as an "'as if' exercise" (2003, p. 289), which, due to the allegorical nature of astrology, can lead to reliable and "real" descriptions of situations, but not necessarily so. Another factor (intuition, psi, divine inspiration) is required to achieve a "bull's-eye."

However, it is precisely the regularity and predictability that makes astrology so fascinating for many people, distinguishing it from "esotericism" for its clientele, as professional practitioners stated in a survey of experts that I conducted in 2016. ${ }^{20}$ When astrologers meet and discuss the birth charts of prominent people such as Donald Trump (as I have witnessed), the structure of the argument does not follow a poetry competition, but rules are applied, discussed, and supported by implicit or explicit "statistical" statements (i.e. frequency and context statements). The mere fact that the symbol system of astrology can be used to communicate reliably with other people who speak this 
astrological "language" via charts and their interpretations should provide sufficient clues to give the "objective," not psi-conditioned or accidental part the right status in astrological practice. ${ }^{21}$

The process of integrating new astrological elements into the canon of astrology also follows rule-based methodological approaches-at least in the somewhat advanced phase and as an important part of the process. ${ }^{22}$ For example, one enters the newly discovered planet Chiron in as many horoscopes as possible of prominent or personally known persons to examine those in which the new planet is placed in a significant position. ${ }^{23}$ In the sense of a data-supported theory formation, it follows to consider which aspects of the persons concerned become better understandable under the inclusion of the new element, and which similarities among the persons with a significantly placed Chiron in the chart can be determined, which becomes easier to explain under the consideration of a new element.

\section{SCIENTIFIC STUDIES ON THE VALIDITY OF ASTROLOGY: PROBLEM AREAS}

With my critique of the way the references to psi processes are used, I am by no means minimizing the importance of subjective aspects in the practice of horoscope interpretation. It is truly a complex process with many degrees of freedom, space for psi processes, and above all human creativity. One can even say that the latter is necessary to produce good interpretations. Just as in music there are "lifeless" and bland interpretations as well as soulful and ingenious interpretations of a composed piece of music, so there are in the interpretations of horoscopes. And just as one cannot say that the "lifeless" interpretation of a musical work of music is "wrong" if the interpreter adheres to the notes, one cannot suggest an unimaginative and uninspired processing of a horoscope is "wrong" as long as the rules of interpretation are adhered to. The interpretations are simply poor and have little meaning when the connection between the symbolic language of astrology and its concretion in the client's individually and collectively shaped environment is not successful. In order to achieve a "bull's-eye" in an interpretation that is beyond the known and effective psychological mechanisms of cognitive illusions such as the Barnum effect, ${ }^{24}$ it is 
necessary to creatively explain a translation of the abstract pattern, or the comparatively abstract structural principles, into the possible concrete events in the lifeworld. ${ }^{25}$ Therefore, the task is to convey how a certain constellation, which may appear contradictory in itself, represents the lifeworld of a certain person with an individual biography marked by hereditary, and by micro- and macro-social as well as general cultural environmental influences. The schematic use of key astrological terms will have little success, and some astrologers who consult in such a rather stereotypical way may quit in frustration if not helped by the aforementioned psychological mechanisms that ensure the experience of mutual, subjective evidence.

\section{Taking the Limits of Validity Seriously}

This complex of necessary "translation work" also accounts for many problems in scientific studies on the validity of astrology. The problems concern what is called "Aussagegrenzen," limits of validity, in revised astrology. According to the theoretical model assumptions of revised astrology, this means that one finds only structural features and character traits in the chart that must be interpreted in relation to external conditions. If, for instance, a "favorable" Mercury position is associated with a pronounced ability to think and communicate, no conclusions can be drawn about the IQ. If there is a severe degree of impairment of the ability to communicate due to a severe mental disability, the "favorable" Mercury position in the birth chart can only be determined in comparison with other severely mentally impaired people. Since, however, there is no agreement among astrologers on the significance of the limits of validity, from the point of view of revised astrology, this leads to regular overestimations of one's own capabilities as an astrologer. For example, in matching experiments, in which astrologers are asked to distinguish horoscopes of 100 smart pupils and 100 mentally retarded pupils and to allocate them to the respective groups (Narlikar et al., 2009), the allocation performance of the astrologers involved was marginally worse than if dice had been thrown. Who would be surprised? Out of 51 astrologers originally involved, 27 gave assessments. In addition to a "natural shrinkage," some of the 24 dropouts may have wisely gained insight and concluded 
that the task could not be solved, while the remaining 27 astrologers delivered their allocations.

I was actively involved in a matching experiment (Wunder, unpublished), the task of which was to write short assessments on two charts. Both charts went to both chart owners. Each person selected the astrological chart interpretation they felt was "suitable" for them. Without going into details: I found this task enlightening because I noticed the difficulty in writing assessments in a way that prevents misunderstanding by the readers (i.e. horoscope-owners), even with sufficiently differing charts. Although it basically was a small task, it proved to be extremely demanding and time-consuming. After I had delivered my two assessments, I left the experiment. I was flattered by my success-the horoscope owners' choices matched their own charts-but with "N equals 1 " this of course counts for nothing. I learned, however, that some astrologers were very eager to participate and worked on many pairs of horoscopes. If one or more of these "zealots" did not have a feel for the linguistic challenge of the task and, moreover, did not observe the limits of validity, this could destroy the results of a whole experiment. This experiment was one of many that put the achievements of astrologers in a bad light and therefore seems to justify further doubts about the basic validity of astrology.

\section{Astrologers' Excuses}

In his paper "Why Astrology Doesn't Work," Kelly lists a number of "Astrologers' Excuses for Failings of Astrology" (1998, p. 533). ${ }^{26}$ Some of the arguments put forward are valid. For example, the statements (excuses): "(p)sychological factors, e.g., client self-insight, maturity, psychological integration, unconscious processes, etc., can modify how the chart is expressed in behavior," and "(b)iological, e.g., age, sex, or sociological factors, e.g., socioeconomic status, culture of origin, spirit of the age, can modify how the chart is manifested in behavior;" are plausible and relate precisely to the limits of validity. "The client lacks self-knowledge" is also a framework condition that cannot be neglected. When designing and validating questionnaires in the field of personality psychology, the distinction between self-image as reflected in self-assessments, self-information, and actual behavioral data, 
is relevant for determining the ecological validity of the measuring instrument. This distinction is also valid in the field of astrology. Finally, the statement "Some astrologers are worse than others" reveals a fundamental point in relation to astrological experiments, whereby the assessment "better" or "worse" should be understood in this context as limited to the experimental situation.

\section{The Role of Experience}

Looking again at the conclusions by Cornelius: He views astrology as divination; extrasensory perception (ASW) or intuition play a decisive role; and experience as an astrologer does not improve the results (2003, p. 67). Cornelius supports this view with two concrete points: (1) the failure of experienced astrologers in classification experiments, e.g., a replication of Clark's classification experiments (Clark, 1960a, 1960b) by Michel Gauquelin (1983, p. 138), in which all experienced astrologers were not able to accomplish the task successfully_including himself (Cornelius, 2003, p. 64f.); and (2) the report of the American astrologer Dal Lee, who participated in one of Clark's tests, scoring quite successfully. He intuitively solved the task in a very short time, without a time-consuming analysis of the charts (Gauquelin \& Sadoul, 1972, p. 243f.; Gauquelin, 1983). In effect, this speaks for a different, more complex process than the usual, thorough, astrological analysis relying on deeper considerations. This interesting single case seems to have led to an over-generalization ultimately driven by a desire to confirm his own theories: Gauquelin wanted to establish his neo-astrology, whereas Geoffrey Dean and Geoffrey Cornelius wanted to largely reduce the anomalistic part of astrology to a psi process.

If further literature is taken into consideration, there are counterexamples showing that the experiences of the astrologers seemed to play a role in success. For example, in a matching experiment to distinguish horoscopes of happy and unhappy spouses, the ten professional astrologers involved performed significantly better than the 17 amateur astrologers (Steffert, 1983). A more impressive, largely overlooked, example in the review literature on astrological experiments, is the DFG project "Investigation of Unaccredited Practices of Interpretation and Counseling" mentioned in Part 1 of this paper 
(previous article), ${ }^{27}$ which the psychologist and physician Hans Bender carried out between 1952 and 1954 with the participation of a total of 178 astrologers. Although the results remained below Bender's high expectations, they were significant ${ }^{28}$ and withstood a critical reanalysis; some statistical errors of the first evaluation were corrected (Timm \& Köberl, 1986). For the discussion here, a feature of interest is that five astrologers clearly stood out from the crowd of all participating practitioners. ${ }^{29}$ Four of them were prominent, very experienced astrologers. $3^{\circ}$ In addition to Thomas Ring (1892-1983), Walter Böer (1914-2007) was one of Hans Bender's regular astrological colleagues at the IGPP in Freiburg (Werthmann, 1971). Fritz Riemann (1902-1979) and Ernst von Xylander (1922-1998) were both psychologists and authors of astrological monographs. Although one can statistically expect with a large number of participating astrologers that some stand out, this top group is characterized by various qualities that make their random formation appear incredible. These astrologers consistently advocated the approach of a revised, psychologically oriented astrology with a strong, scientific orientation, and a clearly, rule-governed practice that they wanted distinguished from astromantics. It can be assumed that they certainly did not exclude the role of intuition or psi in practical interpretation work.

\section{EMPIRICAL INVESTIGATIONS ON THE VALIDITY OF ASTROLOGY}

The correlation experiments by Bender and Clark, which had led to significant findings in both cases, cannot simply be dismissed as the result of intuitive or paranormal performance (e.g., Gauquelin, 1983, pp. 138ff.) despite the largely failed replication attempts. Nor can the attempts to explain away the connections found by Gauquelin between planetary positions and professions of prominent persons convince me. Geoffrey Dean (2000), for example, tries to interpret the correlations mainly as a result of voluntary birth time adjustments of the chart owners by themselves or their parents, with the intention of having a desired planet at the ascendant or medium coeli. Such an explanation is implausible for various reasons, which are not to be discussed here. ${ }^{31}$ Even if one can agree with astrology's critics who do not disqualify the findings of Gauquelin, or the few successful classification tests, and 
emphasize that these results in no way reflect the practical work of the astrologers, an anomalistic perspective is not diminished. The "blackswan principle" applies here. As in experimental parapsychology, where the effects are many dimensions smaller than in lifeworld reports of psi experiences, research on the validity of astrology, I suggest, would be better focused on the investigation of context conditions, in the broadest sense, in order to be able to initially increase the general prospects of success, but then also the effect size. The comparison with parapsychology, in particular, reveals that research in the lifeworld and in the laboratory can stimulate each other (cf. Mayer \& Schetsche, 2012). A categorical statement that Gauquelin's findings and his "neoastrology" as well as the basics of the sparse successful matching experiments have nothing to do with the traditional practice of Western astrology creates a dichotomy, which may be pleasant for skeptics and practicing astrologers and protects the latter from narcissistic offenses ("astrology cannot be empirically investigated in principle!"), but which is not constructive and progressive.

In the following I will address some methodological aspects and problems to be considered in future empirical research on astrology and that have already been considered by prudent researchers familiar with the subject. They can be classified according to the distinction mentioned above between (1) the direct study of the ABT and (2) the study of astrologers' performances.

\section{Methodological Problems in Investigation of the Above-Below Theorem}

In statistical tests where hypotheses concern frequencies of occurrence of certain constellations and aspects and where it is not possible to make a simple comparison of matched groups, the determination of the random expectation is a central problem. This is mainly because astrological variables do not simply behave predictably on the time axis, but are subject to complex rhythmic overlaps (Mayer \& Garms, 2012). Different methods are used to deal with the resulting sampling problems. Ruis (2007/2008, 2012), in his investigation of serial killers, formed a large group of adjusted comparison horoscopes from an astrological database, from which he calculated a random expectation value using the bootstrap method. Furthermore, he created 10,000 
artificial horoscopes from the 77 available horoscopes of serial killers by random recombination of the astrological factors, with which a comparative value could also be calculated. However, the second method, depending on the question, is not without problems because of the effect of the slow-moving planets, a consequence that questions the value of the "shuffling" method. Another method also used by Ruis is the time-shifting method, suitable for testing aspects of fast-moving celestial bodies, i.e. mainly the moon. The actual birthday is shifted step by step, for example, by plus or minus seven days under the assumption that the postulated effect progressively weakens. Nevertheless, the use of this technique is limited to certain investigation designs. In an experiment on astrological synastry, Mayer \& Garms (2012) used the sophisticated method of calculating an individual random expectation value for each pair of birth horoscopes using Monte Carlo simulations, a method that has since become feasible due to the significant increase in computer figuring power. With this technique, the complex superpositions of the orbital movements of the relevant celestial bodies are adequately considered from a geocentric perspective.

Another problem that is almost universally ignored by both astrologers and skeptics is how to deal with the signs of the zodiac in classical studies of the correlation, for example, between sun signs and occupation, noted in the large statistical study by Gunter Sachs, The Astrology File (1999). The astrologer Peter Niehenke (1998) highlighted that while signs of the zodiac represent analytical categories from an astrological perspective, they cannot be treated as discrete facts from an external, scientific, point of view, comparable with biological sex, age, or eye color. The zodiac divided into twelve, thirty-degree, sections with the respective zodiacal sign assignments represents a human construction. The frequently made error in these investigations could be described in the words of ethnologist William Sax: "the academic sin of reification" (Sax, 2010, p. 3). A research object is reified into a natural object, although it is a human construction. An analytical category, like signs of the zodiac is misunderstood as a naturally given property (see also Mayer, 2013); so, if one wants to check the connection between earthly events and planets in zodiacal signs, then one has to test against other divisions of the zodiac for control-take about 45-degree sections, or 20-degree sections, or shift the beginning of a section. 
The direct examination of the ABT usually describes an earthly fact—event, personality trait, career choice—to which correspondences to the astronomical system are sought. Events such as "suicide," "car accident," and "lottery win" are clear facts; however, even though the first-mentioned event is also clear in its consequences, it makes a significant difference whether a car accident caused only a minor loss or whether it is a life-changing event. ${ }^{32}$ And if one makes a small lottery win with three correctly typed numbers out of six, then this may even cause disappointment, because one had hoped for more. A similar problem arises when one takes the fact "marriage." Whether it is marriage for love, a marriage for convenience, or a forced marriage, whether it is happy or unhappy, it must be distinguished in the perspective of revised astrology. ${ }^{33}$ This may seem trivial and self-evident, but often even such modest considerations were not sufficiently considered in astrological investigations and an alleged fact was nonreflectively taken as an unambiguous detail. Thus, the probability of proving a potentially significant correlation is extremely reduced.

Similar caution is required when using questionnaires for selfdisclosure of personality traits. Niehenke (1987) used a comparable method for his extensive astrology study on the relationship between astrological constellations and personality traits, and may have failed due to the discrepancy between idealized self-perception and actual personality profile and behavior, which is a classical issue concerning the validity of personality questionnaires. Astrological prior knowledge can significantly distort answers. This applies not only to consciously acquired, more or less detailed, prior knowledge, but even to the simplest characterizations, such as those that can be read casually in astrological texts in newspapers or on sugar cube packets (Eysenck \& Nias, 1982, pp. 57-60). Psychologist Lance Storm cited as an example of possible causes of a discrepancy between idealizing self-image and underlying psychic structure that the notion of extraverted behavior in a depressive type can be a form of defense mechanism that obscures the actual introverted character of the person. Storm concludes from this that "No conclusions about astrology can be reached from experiments that do not have controls over self-reporting of this kind" (2007, p. 49). 


\section{Methodological Problems with Matching Experiments}

In addition to the investigator's knowledge about the subject of his research, the "quality" of the participating astrologers plays a decisive role in matching experiments. "Quality" as meant here does not refer to the general quality of the astrologer as a counselor. The success of the counseling is the result of many factors, some of which are independent of astrology, and can be based entirely on intuition, psychological empathy, conscious or unconscious cold reading, and, maybe, clairvoyant abilities in combination with well-known cognitive illusions such as the Barnum effect. Therefore, meaningful consultations can also be made on the basis of false horoscopes, accompanied by feelings of high subjective evidence from both the client and the astrologer. "Quality" here refers to an ability to work self-reflexively with the sense of the scientific issue; subsequently, the focus is not on client satisfaction, but on a critical reflection of what one does at work, and on what basis individual interpretations and statements are made. A sensitivity for the limits of validity described above is of central importance. In contrast to Cornelius (see above), who attaches little importance to the astrologer's experience for the outcome of such investigations, I consider it relevant, in principle, if further obligatory conditions such as the consideration of the limits of validity, but also a sensitive handling of the language, e.g., when writing short assessments for clients, are fulfilled.

One point of criticism by astrologers of such classification experiments is that they are artificial situations. The participating astrologers would have to adopt practices that do not correspond to their standard practice, which would make failure understandable. ${ }^{34}$ With a good study design it is possible to meet this objection by adapting the task as closely as possible to the practical situation. This can be done by leaving the technique to be used completely open and allowing questions about the horoscope inquirer, as long as they do not concern points that make an assignment to the horoscopes possible by non-astrological means. Additionally, distortion by simple astrological prior knowledge ("sugar cube packets") 35 can be avoided by keeping the sun sign identical when selecting horoscope pairs. This procedure, however, makes it more difficult to distinguish between the two horoscopes, which is why the participating astrologer should be 
given the option of rejecting a pair of horoscopes and requesting a new one until he considers the distinctness of the two horoscopes to be sufficient. These measures offer a very close proximity of the task to everyday practice and represent improved, experimental conditions for the participants without this being at the expense of experimental control, e.g., with regard to hidden cues. The sociologist Edgar Wunder conducted an equivalent experiment, although it is unpublished. Despite these optimized conditions for the participating astrologers, they, as a whole, could not solve the task beyond chance expectation.

There are two points to keep in mind: (1) Due to the great freedom in terms of the technology used, astrologers and their claims are now being tested to see what they actually accomplish. Astrology as a key system of symbols and interpretations, notwithstanding, is pushed into the background; one simply does not know how it was applied and what role it played in the first place. If it had been successful, it would have been possible to modify various variables in further steps to learn more about the underlying processes. The failure, however, forces an examination of whether the technique used plays a decisive role, perhaps relevant to the observation of limits of validity. (2) Furthermore, the question of what "qualities" are required in astrologers in order to increase the probability of successfully solving the tasks is gaining in importance.

In my own experience with the matching experiment mentioned above, I have experienced how crucial a good feeling for language and a pronounced imagination are when touching the (mis)comprehension possibilities of written assessments. ${ }^{36}$ Accordingly, a careful selection of the participating astrologers as well as a restriction of the technology used seem to be promising measures, similar to the situation in experimental parapsychology where there remains a tendency to work with "gifted" test subjects.

\section{ASTROLOGY AS A SUBJECT OF SCIENCE}

The best possible knowledge of the researcher about the nature of the researched object seems to be a matter of course, but this varies in the field of anomalies. Furthermore, some scientists feel able to make judgments about astrology without knowing how astrological practice works ${ }^{37}$ and even conduct studies on astrology without 
properly understanding what they are investigating. This results in poor or meaningless studies that add to the statistics and are weighted equally as though thoroughly thought-out studies. The few, but nevertheless impressive positive individual findings both on the ABT, and on the field of matching experiments, assign astrology a justified place in anomalistics alongside cultural, historical, social sciences, and religious studies. Expressly, the anomalistic approach requires respectable knowledge of different astrological approaches as well as the mechanisms leading to experiences of subjective evidence in astrologers and clients. Only then is it possible to sufficiently formulate hypotheses in which it is clear what is being tested.

In addition to many unobjective and non-informed criticisms, there are also a number of important critical works on astrology that offer illuminating insights into the process of contemporary, "Western," astrological practices. Dean's "Astrology and Human Judgement" (1998/1999) and Kelly's “Modern Astrology: A Critique" (1997) and "Why Astrology Doesn't Work" (1998), for example, offer unpleasant but nevertheless very important expositions for astrologers that provide a clearer self-understanding for their own actions..$^{38}$ The latter essay, particularly, displays many possibilities for self-immunization, a "closed system" such as adept astrologers are working with, which eventually remains irrefutable due to its complexity. For each failure a (system immanent or external) reason can be found, seemingly more or less plausible-depending on one's own point of view. Still, this does not mean that the ABT, as a scientific anomaly, is not scientifically accessible in general. It also does not mean that astrologers' "excuses" for their failure are necessarily not valid arguments and should therefore not be taken seriously. That would be a logical fallacy. If one does not want to give up astrology as an anomalistic research project-and the few positive findings provide sufficiently good reasons for this - then in my opinion there is no way around an explicit differentiation of astrological practices and the underlying concepts.

Michel Gauquelin has taken the right approach with his concept of "neo-astrology" in that he has abandoned the emic specifications and thus dismissed astrological practice as a reference for his research..$^{39}$ Astrological practice draws on many sources. It can probably best be understood, following Wunder, as an implicit, non-institutionalized 
form of religion, as "a highly privatized and pluralized form of religion that knows no dogmatic canon and no institutions that could guarantee such a canon" (Wunder, 2005, pp. 300f.; emphases in the original). Astrology can be practiced only as divination, in which other anomalistic aspects can play a significant role (synchronicity as meaning-generating "magic of the moment"). Intuition, psychological empathy, knowledge of human nature, imagination, and creativity are important components for a good astrological chart reading, which sufficiently explains how respected consultative astrologers are not necessarily successful in an experimental setting where the client's experience of evidence is not the main focus. According to this complexity of the research subject, there are also different scientific approaches to and questions about astrology, among which the anomalistic one only represents a partial view.

With this paper, an attempt is made to provide an overview of the difficult and diverse relationships between astrology and science. This aim intends to encourage researchers to re-adopt earlier approaches that are increasingly falling into oblivion. Modern databases and data processing offer many new possibilities for researchers. Thereby, studies become possible that were unthinkable 50 years ago. Be that as it may, computing power alone does not guarantee an intelligent and successful study design. A thorough knowledge of astrology in all its variants and aspects is just as important as astrologers being test participants who know their own practices self-reflexively and view them critically.

\section{ACKNOWLEDGMENTS}

I sincerely acknowledge and appreciate the valuable comments and suggestions of the blind reviewers, which helped to improve the manuscript.

\section{NOTES}

1 Bender wrote in his obituary for Thomas Ring: "The evidence of astrological analyses with which Thomas Ring illuminated important situations in my life and in those close to me was one of the strongest motivations of my decision to turn to border areas [of psychology = parapsychology/anomalistics_G.M.]" (Bender, tr. by G.M.). 
2 The item formulation is slightly different in the German version: "Do you believe that there is a connection between the star sign and the personality of the human being?" https://yougov.de/news/2015/07/17/ vor-allem-frauen-glauben-horoskope/

3 Even the wording of the items is often highly problematic to inadequate-due to the ignorance of the subject under investigation that often can be found among the survey designers. For example, Campion (2012, passim, especially p. 87) has pointed out that the phrase "believe in astrology" can be misleading, since astrology is not a matter of faith for those who are more concerned with it and have had their own experiences with its practical application, but rather is linked to evidence experiences, i.e. its "functioning" is an empirical fact for them. A more appropriate formulation would be, for example, "consider it possible..." This problem does not only concern questions about astrology, but also about anomalistic/paranormal topics in general, where experiences of subjective evidence play a crucial role.

4 See Part 1 of this paper (Mayer, 2020, p. 787, Note 41) in this same journal issue. See also Campion (2012, Chapters 12 and 13).

5 The religious scholar Kirstine Munk describes astrology as "a "metalanguage' for the various contemporary divinatory techniques" (2017, p. 17) because of its multiple embedding in and combination with other divinatory systems.

6 What might be regarded as an analogical expression of magic is only valid in this sense as long as a kind of magical interaction is assumed. This is not the case for many contemporary astrologers, since they assume a correlation relationship. Accordingly, McRitchie (2006, pp. 6-7) speaks of a cosmic symmetry between the microcosmic and macrocosmic environments.

7 See Ertel (2011) and Ertel \& Irving (1996) for an overview of Gauquelin's findings, replications, and controversies about these findings.

8 Interaspects are significant angles between the planet positions of two horoscopes.

9 Matching experiments can have a different distance from the direct 
testing of the ABT: If the correct horoscope is to be selected for a person from a pair of horoscopes in which one has been created with the correct birth time and the other with a changed birth time, the proximity to the direct examination of the $A B T$ is greater than with the matching task, for example, of horoscopes to certain professions.

${ }^{10}$ For Thomas Ring's astrological anthropology, see Part 1 of this paper (preceding article). For the significance of the moment of birth in the view of revised astrology, see also Niehenke (1994, pp. 24-34).

"Since this model does not assume a direct causal-physical influence of the planets on earthly events, but rather a correlative relationship, the skeptical argument that the physical (gravitational) forces are too weak to exert an effect due to the large astronomical distances is futile.

${ }_{12}$ Thomas Ring (1972, p. 139) writes: "In general, astrology can only be spoken of as long as it starts from a measurable cosmic state of facts; this is precisely what distinguishes it from forms of manticism, of which one variation, 'astromanticism,' arbitrarily sets celestial symbols." An example of such an astromantic card deck is The Enchanted Astrologer (Farber \& Zerner, 2002), whose authors promise immediate "in-depth" answers to personal questions.

${ }^{13}$ The fact that the technique of horary astrology is nevertheless not as simple as its basic structure seems to promise is due to various framework conditions and interpretation restrictions that must be observed. With the new complexity introduced, despite the relatively simple, unambiguous, and fixed basic structure, there are degrees of freedom of interpretation with which "wrong" answers can be justified.

${ }^{14}$ In the Dictionary of Gnosis \& Western Esotericism (Hanegraaff, 2006), the following definition is given: "Divination, in general, is the art of divining the past, present, and future by means of various techniques" (Charmasson, 2006, p. 313). However, this definition does not reference the sacred, otherworldy, or divine realm-Curry referred to this as "an ongoing dialogue with more-than-human agents" (Curry, 2010, pp. 114-115). There are useful subtypes of divination, e.g., the divinatio naturalis and the divinatio artificiosa 
(Charmasson, 2006, p. 313). But for the purpose of this paper, a rather simple definition by Greer (2003, p. 134) captures the essence: "[Divination is] the art and science of obtaining information by occult means..."." "Occult means" directly references the paranormal or supernatural without being specific about ritual or tradition. What I call "pure divination" means a technique that mainly is based on the use of occult (= synchronistic, paranormal, supernatural) means and ideas and consists essentially of "an act of aleatory randomization" (Curry, 2010, p. 115). With regard to astrology, the astromanticism mentioned above falls in this category.

${ }^{15}$ Dean et al. (2016) provide a critical overview of the state of research of empirical tests in astrology.

${ }^{16}$ Stephen Braude, who is neither a skeptic nor an absolute believer in astrology, gives in the "Postscript" of his book The Gold Leaf Lady and Other Parapsychological Investigations an impressive example of extremely successful predictions by means of astrological prognosis (2007, pp. 153-175). However, the account is based on personal experiences with his wife Gina, a gifted astrologer, and does not refer to formal experiments. Although his wife has developed her own and apparently quite unique astrological technique that seems to allow such accurate predictions, he doubts that the success is due solely to astrological practice and considers substantial psi to be a decisive factor.

${ }^{17}$ There is a constructivist secular interpretation of astrology as a "useful kind of fiction," which also renounces the claim of objectivity of astrological laws, focuses on the counseling situation between astrologer and client, and sees in the work of the astrologer a kinship to that of an artist (Weidner, 2002). For criticism, see Mayer (2002).

${ }^{18}$ In a similar sense, Sigmund Freud provides a respective example in his text "Psychoanalysis and Telepathy." A "fortuneteller" visited by one of his patients predicted a very concrete event based on the date of birth of a person and related astrological calculations: “... next July or August this person would die of crab or oyster poisoning" (Freud, 1970, p. 61). With this prognosis she did not score a full hit because the person in question — the patient's brother-in-law-had suffered 
from crab poisoning nearly killing him a year earlier in August. Freud interpreted this as a case of telepathy and sees astrology in the following function:

... the purpose of the fortuneteller's astrological work was to divert her own intra-psychic forces, and to occupy them innocuously. This made it possible for her to become receptive and permeable to the impact of thought of others, and enabled her to become a genuine 'medium'. (ibid., p. 62)

Whether Freud's determination of the function of astrology is completely correct in this case is more doubtful. If we follow him on the assumption that conventional explanations are inadequate for this "almost hit," then it is likely that astrological reasoning would have given direction. For example, a difficult constellation involving Neptune ("poisonings") and the Sun could be interpreted as corresponding existential threats, which, due to the retrogression of Neptune, could also have been encountered in a similar way a year earlier. Freud, however, disagrees with that: "Let us not forget how many people are born on the same day. Is it conceivable that the community of fate which may be determined by the date of birth would include such details?" (Freud, 1970, p. 61). If interpreted favorably, we would be dealing here with a combination of astrological considerations and clairvoyance. The not-so-favorable interpretations are to be renounced at this point.

19 In a sense, this is reminiscent of discussions in parapsychology, where the question of the validity of laboratory experiments concerning the occurrence of psi in the living world is also repeatedly discussed (e.g., Alvarado, 2019; Braude, 1986, pp. 1-58; Mayer \& Schetsche, 2019a, 2019b).

${ }^{20}$ See part 1 of this article in this journal issue (Mayer, 2020:, p. 787, Note 41). One astrologer noted that in about a quarter of the initial astrological conversations, the demarcation between astrology and esotericism was discussed and that this was an important point for clients. One astrologer said, pointing in a similar direction: "Many (customers) have read something, recognized something of themselves." This individual reference to astrology is based on 
objective facts that cannot be found, for example, in card readingpeople feel that astrology is more complex and more serious than many other offers from the esoteric sector.

${ }^{21}$ One can quite reliably draw conclusions about the underlying chart from written astrological expertise, even if no technical terms are used; it is also possible to program software that-with all the limitations-generates reasonably meaningful, and for an astrologer himself understandable in its contradictions, interpretation texts.

${ }^{22}$ In the first phase after discovery and integration, however, other factors such as intuition and/or paranormal aspects play a role, such as with the naming of Pluto. The name was suggested by an eleven-year-old girl and then prevailed in the decision-making process (Rincon, 2006). In terms of the astrological significance later attributed to astrologers on the basis of their studies of horoscopes, it was a bull's-eye. See also https://www.astro.com/astrowiki/en/Pluto regarding the naming.

${ }^{23}$ At least this should be the way of choice from a scientific perspective. In a preliminary remark to his description of the planet Pluto ( $\underset{+}{)}$ ), Ring writes in Volume 1 of his Astrologische Menschenkunde:

With an elemental force [Wesenskraft] that has only been in the sphere of investigation for about 20 years, much caution is required and no conclusive statement can be made. However, the orbital elements of $\stackrel{q}{q}$ are sufficiently known to be able to calculate its position in the charts of historical personalities. This shows an aboveaverage frequency of emphasis, be it through ${ }_{+}$-position at one of the cardinal points of the sphere of interest, be it through a strong aspect to the main symbols of life [= planets]. Many traits of these personalities find a sufficient explanation only after $\stackrel{+}{q}$ is introduced in a provisionally hypothetical meaning, and this again leads to the observation of the living. The results are presented here as preliminary, stimulating further investigation. (Ring, 1956, p. 234, translation by the author G. M.)

Unfortunately, many astrology authors lack this appropriate caution nowadays (cf. Kelly, 1997, 2005).

${ }^{24}$ Dean et al. (1998/1999) offer an excellent overview of such mechanisms related to astrology. 
${ }^{25}$ Lifeworld is a translation of the German sociological and philosophical term "Lebenswelt." It refers to the world as it is experienced and culturally shared. In parapsychology, psi phenomena in lifeworld (spontaneous psi phenomena) are contrasted with psi phenomena elicited in the artificial situation of laboratory experimental research (cf. Mayer \& Schetsche, 2012).

${ }^{26}$ Kelly thereby draws on the work of the sociologist Wedow (1976).

${ }^{27}$ Unfortunately, there was no formal publication of the results of this extensive investigation. The DFG final report and other documents can be found in the archive of the IGPP (signatures: E/20, 40/3, and $\mathrm{E} / 23 \mathrm{~A}$ ). It was not until 1986 that Timm \& Köberl published the reanalysis of this project in a scientific journal. Annoyingly, this significant finding is not reproduced in the volume Tests of Astrology by Dean et al. (2016), although the reference is mentioned. Instead, reference is made to an evaluation of the study by a Mr. Hoerner (1983), who, in clear deviation from Timm and Köberl and without naming any further details, comes to the result: "The result was just chance" (Dean et al., 2016, p. 420). Surprisingly, the authors seem to prefer the notes of a statistics student in a newsletter (The Explorer) to the thorough work of Timm and Köberl.

${ }^{28}$ See the IGPP archive (signatures: E/2O, 40/3 and E/23A).

${ }_{29}$ See p. 766 , and p. 782, Note 22 in Part 1 of this paper (Mayer, 2020) in this same journal issue.

${ }^{30}$ The fifth astrologer of the "top group ..., who had stood out from the total of well over one hundred" (Werthmann, 1971, p. 190) was Willy Probst from Graz, Austria, who also did graphology, but for whom I could not find any other information. Graphology was part of academic psychological diagnostics between 1950 and the beginning of the 1970s and has been offered as a compulsory course for psychology students at the Psychological Institute of the University of Freiburg since 1959 (Fahrenberg, 2017).

${ }^{31}$ For criticism, see Ertel (2000). A result by Müller and Menzer (1993) also speaks against this thesis. The two authors had examined the birth charts of 1145 members of German dynasties for planetary 
effects in the sense of Gauquelin-without being able to prove significant correlations. The authors saw an explanation for this in the fact that the sample fulfilled only the selection criteria of Gauquelin for celebrity to a limited extent. But they found a statistically significant correlation concerning a subgroup of early deceased with a maximum age of 15 months. At birth, Saturn was often found in the so-called "G-zones," i.e. in the 12th house at the ascendant and in the gth house at the medium coeli, which was appropriate from an astrological perspective (however, this is a post hoc finding that would require replication with other data). Especially the classical attribution as "bringer of misfortune" does not make it plausible that parents would put Saturn in a prominent position by "birth time tampering" (see also McRitchie, 2016).

${ }^{32}$ In herstudy on the relationship between solar transits and occupational accidents, Klein took, as an inclusion criterion, a disability of at least 3 months, which is a fairly reliable indicator of the severity of the event (Klein, 1993). The correlation study revealed highly significant correlations; see also the critical commentary by Dean et al. (2016, pp. 224-225), which refers, among other things, to an unsuccessful replication in Sweden but which ignores an important aspect (McRitchie, 2013).

33 In Steffert's (1983) study, astrologers were able to distinguish the charts of happy couples from those of unhappy ones in a matching experiment. Shanks \& Steffert (1984) found in happy couples the moon in so-called "sensitive zones" (according to the Gauquelin system) more frequently than simply by random chance, in which they differed from the unhappy couples.

${ }^{34}$ Cf. McRitchie (2016).

35 This refers to simple descriptions of zodiac signs that were found for many years on sugar cube packets in cafés in Germany.

${ }^{36}$ Klein (1988) conducted a matching experiment in which participants were asked to rank five astrology-based descriptions according to the degree of coherence with their actual partner experience. Many excused their delayed return by saying that the task was too diffi- 
cult due to the great similarity between the five descriptions-a clear indication of the language challenge involved in writing such texts against a background of maximum distinctiveness.

${ }^{37}$ Notorious in this context is the "Statement of 186 leading scientists against astrology" initiated by skeptics and published in 1975 in the journal The Humanist (cf. Feyerabend, 1990, pp. 181-189).

${ }^{38}$ One considerable drop of bitterness, however, remains: One is confronted again and again with the skeptical "bias" of these works, which goes beyond a justified and scientifically founded critical attitude. To give just one example, one wonders why Kelly-in the extended version of his 1997 essay ("Modern Astrology: A Critique"), which he published online under the title "The Concepts of Modern Astrology: A Critique"- -unexpectedly cites a theological counterargument to criticize the astrological concept of a "true identity" expressed by the horoscope:

The notion of 'our true identity' for example, is one which many empiricists, post-modernist philosophers, and Buddhists would consider problematic. The Buddhists consider talk of an essential core of one's being illusory, while post-modernists would consider such talk of 'our true identities' a modernist illusion. (Kelly, 2005)

See also McRitchie's critique of Dean and Kelly's paper "Is Astrology Relevant to Consciousness and Psi?" (2003), in which he addresses unfounded accusations, over-generalizations, and exaggerated assertions to the authors (McRitchie, 2016).

39 However, one does not have to support his conclusions-at least not from the perspective of a revised astrology that does not take the concretions but the structure of meaning as the core of a statement. His findings do not necessarily contradict this. This is not the place to discuss the possible compatibility of Gauquelin's findings with "traditional" astrological symbolism. It should only be pointed out that the characteristic of the celebrity of the persons for whom Gauquelin has found his significant correlations could play a decisive role in understanding the unusual house positions (the so-called Gauquelin sectors). 


\section{REFERENCES}

Alvarado, C. S. (2019). The place of spontaneous cases in parapsychology. In G. Mayer (Ed.), N equals 1: Single case studies in anomalistics (pp. 43-77). LIT.

Bender, H. (1984). Thomas Ring zum Gedächtnis. Zeitschrift für Parapsychologie und Grenzgebiete der Psychologie, 26, 225-227.

Braude, S. E. (1986). The limits of influence psychokinesis and the philosophy of science. Routledge \& Kegan Paul.

Braude, S. E. (2007). The gold leaf lady and other parapsychological investigations. University of Chicago Press.

Campion, N. (2012). Astrology and popular religion in the modern West: Prophecy, cosmology and the New Age movement. Ashgate.

Campion, N., \& Greene, L. (2011). Astrologies: Plurality and diversity: Introduction. In N. Campion \& L. Greene (Eds.), Astrologies: Plurality and diversity: The proceedings of the eighth annual conference of the Sophia Centre for the Study of Cosmology in Culture, University of Wales, Trinity Saint David, 24-25 July 2010 (pp. 1-15). Sophia Centre.

Charmasson, T. (2006). Divinatory arts. In W. J. Hanegraaff (Ed.), Dictionary of gnosis \& Western esotericism (pp. 313-319). Brill.

Clark, V. E. (1960a). An investigation of the validity and reliability of the astrological technique. In Search, 2(4), 44-69.

Clark, V. E. (1960b). An investigation of/and reliability of the astrological technique: Part II. In Search, 2(3), 25-33.

Cornelius, G. (1998). Is astrology divination and does it matter? The Mountain Astrologer, (81). http://cura.free.fr/quinq/olgfcor.html

Cornelius, G. (2003). The moment of astrology: Origins in divination (Rev. and expanded 2nd ed.). Wessex Astrologer.

Cornelius, G. (2010). Interview (Recorded 1oth July 1998; Interviewer: Gary Phillipson). http://www.astrozero.co.uk/geoffrey_cornelius_interview.pdf

Curry, P. (1989). Prophecy and power: Astrology in early modern England. Princeton University Press.

Curry, P. (2010). Embodiment, alterity and agency: Negotiating antinomies in divination. In P. Curry (Ed.), Divination: Perspectives for a new millenium (pp. 85-117). Ashgate.

Dean, G. (1977). Recent advances in natal astrology: A critical review 1900-1976. Astrological Association.

Dean, G. (2000). Attribution: A pervasive new artifact in the Gauquelin data. Astrology under Scrutiny, 13(Special issue), 1-87.

Dean, G., \& Kelly, I. (2003). Is astrology relevant to consciousness and psi? Journal of Consciousness Studies, 10(6-7), 175-198.

Dean, G., Kelly, I. W., \& Maher, A. (1998/99). Astrology and human judgement: Discourse for key topic 4. Correlation, 17(2), 24-71. 
Dean, G. A., Mather, A., Nias, David, K. B., \& Smit, R. (Eds.). (2016). Tests of astrology: A critical review of hundreds of studies. AinO.

Ertel, S. (1998). Astro-Quiz: Can astrologers pick politicians from painters? Correlation, 18(1), 3-8.

Ertel, S. (2000). Gauquelin's planetary effects-Made up by superstitious parents?: On Geoffrey Dean's erroneous grand notion. Astrology under Scrutiny, 13(1/2), 73-84.

Ertel, S. (2011). Rückblick (1955-2005) auf die durch Michel Gauquelin entfachte Forschung. In U. Voltmer \& R. Stiehle (Eds.), Astrologie \& Wissenschaft (pp. 280-323). Chiron.

Ertel, S. (2015). Astrologie auf dem Prüfstand der Statistik. In G. Mayer, M. Schetsche, I. Schmied-Knittel, \& D. Vaitl (Eds.), An den Grenzen der Erkenntnis: Handbuch der wissenschaftlichen Anomalistik (pp. 315-331). Schattauer.

Ertel, S., \& Irving, K. (1996). The tenacious Mars effect. Urania Trust.

Eysenck, H. J., \& Nias, D. (1982). Astrology: Science or superstition? M. T. Smith.

Fahrenberg, J. (2017). Geschichte des Instituts für Psychologie in Freiburg: von der Vorgeschichte der Psychologie bis ca. 2000.

https://doi.org/10.6094/UNIFR/12975

Farber, M., \& Zerner, A. (2002). The enchanted astrologer. Thomas Dunne.

Feyerabend, P. (1990). Erkenntnis für freie Menschen. Suhrkamp.

Freud, S. (1970). Psychoanalysis and telepathy. In G. Devereux (Ed.), Psychoanalysis and the occult (pp. 56-68). International University Press.

Gauquelin, M. (1957/1958). Der Einfluss der Gestirne und die Statistik. Zeitschrift für Parapsychologie und Grenzgebiete der Psychologie, 1(2/3), 102-123.

Gauquelin, M. (1983). The truth about astrology. Blackwell.

Gauquelin, M., \& Sadoul, J. (1972). Les trois faces de l'astrologie sacrée, profane, scientifique. Retz.

Greer, J. M. (2003). The new encyclopedia of the occult. Llewellyn. Hanegraaff, W. J. (Ed.) (2006). Dictionary of Gnosis \& Western esotericism. Brill. Hoerner, S. v. (1983). A truth test for astrology. The Explorer, 1(2), 9.

Jung, C. G. (1957/1958). Ein astrologisches Experiment. Zeitschrift für Parapsychologie und Grenzgebiete der Psychologie, 1, 81-92.

Kelly, I. W. (1997). Modern astrology: A critique. Psychological Reports, 81, 1035-1066. Kelly, I. W. (1998). Why astrology doesn't work. Psychological Reports, 82, 527-546.

Kelly, I. W. (2005). The concepts of modern astrology: A critique. http://www.astrology-and-science.com/A-conc2.htm

Klein, M. (1988). The accuracy of relationship description as a test of astrology. Correlation, 8(2), 5-17.

Klein, S. (1993). Astrologically predictable patterns in work related injuries: "Avert the danger that has not yet come." Kosmos, 22(3), 21-30.

Klöckler, H. (1989). Astrologie als Erfahrungswissenschaft. Diederichs.

Kochunas, B. (2000). Why astrology works. The Mountain Astrologer, 13(1), 35-40. 
https://www.mountainastrologer.com/standards/editor\%275\%20choice/ articles/why_ast.html

marktmeinungmensch. (2017). http://www.marktmeinungmensch.at/studien/ umfrage-zur-einstellung-zu-astrologie-sternzeichen/

Mayer, G. (2002). Die konstruktivistische Versuchung. Zeitschrift für Anomalistik, 2, 208-211.

Mayer, G. (2013). Fehler der Verdinglichung. Kommentar zu Katharina Schüller: "Drum prüfe, wer sich ewig bindet . . . Zusammenhangsanalyse von Standesfällen (Eheschließungen, Scheidungen) und Tierkreiszeichen am Beispiel der Schweiz in den Jahren 1997 bis 2005." Zeitschrift für Anomalistik, 13, 385-387.

Mayer, G. (2020). Astrology and science: A precarious relationship. Part 1: Historical review of German astrology in the 2oth century and current developments. Journal of Scientific Exploration, 34(4), 757-793.

Mayer, G., \& Garms, M. (2012). Resonance between birth charts of friends: The development of a new astrological research tool on the basis of an investigation into astrological synastry. Journal of Scientific Exploration, 26(4), $825-853$.

Mayer, G., \& Schetsche, M. (2012). Die Beobachtung anomalistischer Phänomene in Lebenswelt und Labor. In W. Ambach (Ed.), Experimentelle Psychophysiologie in Grenzgebieten (pp. 273-292). Ergon.

Mayer, G., \& Schetsche, M. (2019a). Introduction: Research logic, models, and particularities. In G. Mayer (Ed.), N equals 1: Single case studies in anomalistics (pp. 11-41). LIT.

Mayer, G., \& Schetsche, M. (2019b). Introduction: Single case studies in anomalistics. In G. Mayer (Ed.), N equals 1: Single case studies in anomalistics (pp. 81-85). LIT.

Mayer, G., Schetsche, M., Schmied-Knittel, I., \& Vaitl, D. (2015). Wissenschaftliche Anomalistik zur Einführung. In G. Mayer, M. Schetsche, I. SchmiedKnittel, \& D. Vaitl (Eds.), An den Grenzen der Erkenntnis: Handbuch der wissenschaftlichen Anomalistik (pp. 1-11). Schattauer.

McRitchie, K. (2006). Astrology and social sciences: Looking inside the black box of astrological theory. Correlation, 24(1), 5-20.

McRitchie, K. (2013). Injury event indicators in the Sara Klein Ridgley astrological research: Review of "Astrologically predictable patterns in work related injuries." http://www.astrologicalreviewletters.org/2013/o8/sara-ridgley.html

McRitchie, K. (2016). Clearing the logjam in astrological research: Commentary on Geoffrey Dean and Ivan Kelly's article 'Is astrology relevant to consciousness and psi?' Journal of Consciousness Studies, 23, 153-179.

Müller, A. (1957/1958). Eine statistische Untersuchung astrologischer Faktoren bei dauerhaften und geschiedenen Ehen. Zeitschrift für Parapsychologie und 
Grenzgebiete der Psychologie, 1(2/3), 93-101.

Müller, A., \& Menzer, G. (1993). 1145 Angehörige deutscher Dynastien [1145 members of German dynasties]. In Series Astro-Forschungs-Daten, Bd. 4. A. P. Müller.

Munk, K. (2017). Signs of the times: Cosmology and ritual practice on modern, Western astrology. Ph.D. dissertation submitted January 2007, Dept. of Philosophy, Education and Religion, University of Southern Denmark. Akademisk bibliotek. Museum Astrologicum.

Narlikar, J. V., Kunte, S., Dabholkar, N., \& Ghatpande, P. (2009). A statistical test of astrology. Current Science, 96(5), 641-643.

NSF. (Ed.). (2014). Science and engineering indicators 2014. National Science Foundation (NSF) / National Center for Science Engineering Statistics (NCSES). https://www.nsf.gov/statistics/seind14/index.cfm/overview

Niehenke, P. (1987). Kritische Astrologie. Aurum.

Niehenke, P. (1994). Astrologie: Eine Einführung. Reclam.

Niehenke, P. (1998). The astrology file, scientific proof of sun sign effects? Correlation, $17(1)$, 41-44.

Rincon, P. (2006). The girl who named a planet. http://news.bbc.co.uk/2/hi/science/ nature/4596246.stm

Ring, T. (1956). Astrologische Menschenkunde, Band 1: Kräfte und Kräftebeziehungen (2nd ed.). Bauer.

Ring, T. (1959). Astrologische Menschenkunde, Band 2: Ausdruck und Richtung der Kräfte (2nd ed.). Bauer.

Ring, T. (1969). Astrologische Menschenkunde, Band 3: Kombinationslehre. Bauer.

Ring, T. (1972). Astrologie ohne Aberglauben. Econ Verlag.

Ring, T. (1973). Astrologische Menschenkunde, Band 4: Das lebende Modell. Bauer.

Ring, T. (1975). Existenz und Wesen in kosmologische Sicht. Aurum.

Ruis, J. (2007/2008). Statistical analysis of the birth charts of serial killers. Correlation, 25(2), 7-44.

Ruis, J. (2012). The birth charts of male serial killers: Evidence of astrological effects? Correlation, 28(2), 8-27.

Sachs, G. (1999). The astrology file: Scientific proof of the link between the star signs and human behaviour. Orio.

Sax, W. S. (2010). Ritual and the problem of efficacy. In W. S. Sax, J. Weinhold, \& J. Quack (Eds.), The problem of ritual efficacy (pp. 3-16). Oxford University Press.

Schmidtchen, G. (1957). Soziologisches über die Astrologie: Ergebnisse einer Repräsentativ-Befragung. Zeitschrift für Parapsychologie und Grenzgebiete der Psychologie, 1(1), 47-72.

Shanks, T., \& Steffert, B. (1984). Planets and happiness in marriage. AstroPsychological Problems, 2(3), 5-9.

Steffert, B. (1983). Reductionist versus wholistic judgements of horoscopes. AstroPsychological Problems, 1(2), 24-29. 
Storm, L. (2007). Psi, divination and astrology: A brief introduction. Australian Journal of Parapsychology, 7(1), 47-51.

Timm, U., \& Köberl, T. (1986). Re-Analyse einer Validitätsuntersuchung an 178 Astrologen. Zeitschrift für Parapsychologie und Grenzgebiete der Psychologie, 28, 33-55.

TNS Infratest. (2012). https://de.statista.com/statistik/daten/studie/219140/ umfrage/glaube-an-horoskope/

Wedow, S. M. (1976). The strangeness of astrology: An enthnography of credibility process. In W. Arens \& S. P. Montague (Eds.), The American dimension: Cultural myths and social realities (pp. 181-193). Alfred.

Weidner, C. A. (2002). Astrologie-Eine nützliche Fiktion. Zeitschrift für Anomalistik, 2, 197-204.

Werthmann, H.-V. (1971). Astrologie und Psychologie-Eine vergleichende experimentelle Studie: Teil I: Versuchsplanung- und Durchführung. Zeitschrift für Parapsychologie und Grenzgebiete der Psychologie, 13, 176-191.

Willis, R., \& Curry, P. (2004). Astrology, science and culture. Berg.

Wunder, E. (2005). Religion in der postkonfessionellen Gesellschaft: Ein Beitrag zur sozialwissenschaftlichen Theorieentwicklung in der Religionsgeographie. Heidelberg University Dissertation, 2004. Geographie: Vol. 5. Steiner.

YouGov. (2015). https://yougov.de/news/2015/07/17/vor-allem-frauen-glauben-horoskope/ https://d25d2506sfb94s.cloudfront.net/cumulus_uploads/document/w9yd48otgr/ InternalResults_150702_star_signs_Website.pdf

https://today.yougov.com/topics/lifestyle/articles-reports/2015/07/06/14-believehoroscopes-can-tell-future 